\title{
Conjugative plasmid pAW63 brings new insights into the genesis of the Bacillus anthracis virulence plasmid pXO2 and of the Bacillus
} thuringiensis plasmid pBT9727

\author{
Géraldine A Van der Auwera1, Lars Andrup² and Jacques Mahillon*1
}

\begin{abstract}
Address: ${ }^{1}$ Laboratory of Food and Environmental Microbiology, Université catholique de Louvain, Croix du Sud 2/12, B-1348 Louvain-la-Neuve, Belgium and 2National Institute of Occupational Health, Lersø Parkallé 105, DK-2100 Copenhagen, Denmark

Email: Géraldine A Van der Auwera - vanderauwera@mbla.ucl.ac.be; Lars Andrup - la@ami.dk; Jacques Mahillon* - mahillon@mbla.ucl.ac.be

* Corresponding author
\end{abstract}

Published: 26 July 2005

BMC Genomics 2005, 6:103 doi:10.1 |86/|47|-2164-6-103
Received: 09 May 2005

Accepted: 26 July 2005

This article is available from: http://www.biomedcentral.com/I47I-2/64/6/103

(c) 2005 Van der Auwera et al; licensee BioMed Central Ltd.

This is an Open Access article distributed under the terms of the Creative Commons Attribution License (http://creativecommons.org/licenses/by/2.0), which permits unrestricted use, distribution, and reproduction in any medium, provided the original work is properly cited.

\begin{abstract}
Background: Bacillus cereus, Bacillus anthracis and Bacillus thuringiensis belong to the genetically close-knit Bacillus cereus sensu lato group, a family of rod-shaped Gram-positive bacteria. pAW63 is the first conjugative plasmid from the $B$. cereus group to be completely sequenced.

Results: The 7I,777 bp nucleotide sequence of pAW63 reveals a modular structure, including a $42 \mathrm{~kb}$ tra region encoding homologs of the Type IV secretion systems components VirBI I, VirB4 and VirD4, as well as homologs of Gram-positive conjugation genes from Enterococcus, Lactococcus, Listeria, Streptococcus and Staphylococcus species. It also firmly establishes the existence of a common backbone between pAW63, pXO2 from Bacillus anthracis and pBT9727 from the pathogenic Bacillus thuringiensis serovar konkukian strain 97-27. The alignment of these three plasmids highlights the presence of well conserved segments, in contrast to distinct regions of high sequence plasticity. The study of their specific differences has provided a three-point reference framework that can be exploited to formulate solid hypotheses concerning the functionalities and the molecular evolution of these three closely related plasmids. This has provided insight into the chronology of their divergence, and led to the discovery of two Type II introns on PAW63, matching copies of the mobile element IS23 I L in different loci of pXO2 and pBT9727, and the identification on pXO2 of a $37 \mathrm{~kb}$ pathogenicity island (PAI) containing the anthrax capsule genes.

Conclusion: The complete sequence determination of pAW63 has led to a functional map of the plasmid yielding insights into its conjugative apparatus, which includes T4SS-like components, as well as its resemblance to other large plasmids of Gram-positive bacteria. Of particular interest is the extensive homology shared between pAW63 and pXO2, the second virulence plasmid of $B$. anthracis, as well as PBT9727 from the pathogenic strain B. thuringiensis serovar konkukian strain 9727.
\end{abstract}

\section{Background}

The Bacillus cereus sensu lato family of rod-shaped Grampositive bacteria contains six subspecies that are geneti- cally very close [1] but nonetheless have highly specialized lifestyles, especially as concerns their respective virulence spectra. Most notable are B. cereus sensu stricto, 
an opportunistic pathogen which has been implicated in food poisoning [2] and endophtalmitis [3], B. anthracis, the etiological agent of anthrax [4], and B. thuringiensis which produces $\delta$-endotoxin crystals that are toxic to insect larvae [5]. These subspecies are thought to have emerged from a common ancestor following a series of genetic rearrangements mediated inter alia by mobile DNA elements (transposons, insertion sequences and phages), in synergy with various mechanisms of horizontal gene transfer (conjugation, transduction or transformation), leading to the acquisition of virulence genes. This is exemplified by the presence of large virulence plasmids in B. anthracis (pXO1 and pXO2) [6], emetic strains of $B$. cereus [7] and B. thuringiensis that carry the genes responsible for the main phenotypic properties by which these bacteria can be distinguished.

While the inter- and intra-molecular movements of mobile elements can obviously have major consequences for the organization and composition of the host genome, it is probably the mechanism of conjugation that best enables the dispersion of these elements throughout the gene pool. Several conjugation systems have been described in Gram-negative bacteria, all of them involving the formation of a sex pilus to bring the participants in close contact, followed by the actual transfer of genetic material via a type IV secretion system (T4SS) [8]. There is much less data available concerning conjugation among Gram-positive bacteria, but the present consensus distinguishes four main transfer strategies, the most common of which seems to be that of the so-called broad host range plasmids. At present, the best characterized of these are the multiresistance plasmids pSK41 [9] and pGO1 [10] from Staphylococcus, pRE25 [11] from Enterococcus, pMRC01 [12] from Lactococcus and pIP501 [13] from Streptococcus as recently reviewed by Grohmann and coworkers [14].

The broad-host-range conjugative plasmid pAW63 was identified in B. thuringiensis serovar kurstaki, where it displays an efficient ability to conjugate in liquid medium, both for its own transmission (around $10^{-3}$ transconjugants per donor in broth mating, up to a frequency of $1: 1$ between kurstaki strains) as well as that of small mobilizable plasmids [15]. Moreover, heterologous conjugation experiments have shown that it is also capable of transfer to its cousins $B$. thuringiensis serovar israelensis and $B$. cereus, as well as to Bacillus sphaericus, Bacillus licheniformis [15] and less closely related species such as Listeria innocua and Enterococcus faecalis (A. Wilcks, pers. comm.; G. Van der Auwera and J. Mahillon, unpublished).

In the present study, the complete sequence determination of pAW63 has led to a functional map of the plasmid yielding insights into its conjugative apparatus, which includes T4SS-like components, as well as its resemblance to other large plasmids of Gram-positive bacteria. Of particular interest is the extensive homology shared between pAW63 and pXO2, the second virulence plasmid of $B$. anthracis [16], as well as pBT9727 from the pathogenic strain B. thuringiensis serovar konkukian strain 97-27 [17].

\section{Results \\ pAW63 is a 7I,777 bp circular molecule}

The complete nucleotide sequence of pAW63 was determined to be 71,777 bp long with a G+C content of $33.8 \%$. Analysis of the coding content and organization revealed few intergenic regions, and a total of 76 coding sequences (CDSs) were identified (Fig. 1), of which all but 8 were found to be in the same orientation (defined as counterclockwise). Interestingly, these 8 CDSs were all located in close proximity to each other, and one of these (CDS 47) corresponded to a component of the pAW63 replicon, which was isolated and sequenced in a previous study [18] while several others were later assigned putative functions as mobile genetic elements as detailed further in the text. The sequence was found to have an $81 \%$ coding ratio with an average CDS length of $768 \mathrm{bp}$. The largest CDS identified was CDS 26, weighing in at 4,248 bp. Several CDSs were associated to distinct spikes in $\mathrm{G}+\mathrm{C}$ composition and will be discussed individually. The BLAST similarity searches showed that most of the 76 predicted CDSs encoded proteins with similarity to proteins from other organisms, although 36 of these were hypothetical proteins and only 26 could be attributed biological functions, while 14 of the predicted genes did not have any known homologs at all. The 26 genes encoding proteins with discernible functions were assigned to functional categories according to a classification scheme adapted from Riley [19]. The physical details and relevant BLAST hit results (scored by percentage of amino acid identity) of all 76 CDSs are summarized in Table 1.

\section{pAW63 generic relationships}

Most of the significant similarity results originated from Gram-positive bacteria species such as Enterococcus spp., Streptococcus spp., Staphylococcus spp., Lactococcus spp. and Listeria spp. in addition to Bacillus halodurans, Bacillus subtilis, Bacillus licheniformis and the members of the B. cereus sensu lato group. It is of particular interest to note that out of the 76 CDSs predicted on pAW63, 50 CDSs showed strong similarity (between 48.8 and $98.7 \%$ amino acid identity, with an average of $81.1 \%$ ) to CDSs found on pXO2 from B. anthracis [GenBank:NC_007323] and 49 CDSs showed strong similarity (between 43.8 and $97.4 \%$ amino acid identity, with an average of $70.5 \%$ ) to pBT9727 from B. thuringiensis serovar konkukian [GenBank: CP_000047], with 42/76 (55.3\%) of these CDSs being shared by all three plasmids. This was consistent with previous observations of sequence similarities between these plasmids $[18,20,21]$. 
[76]

[3]

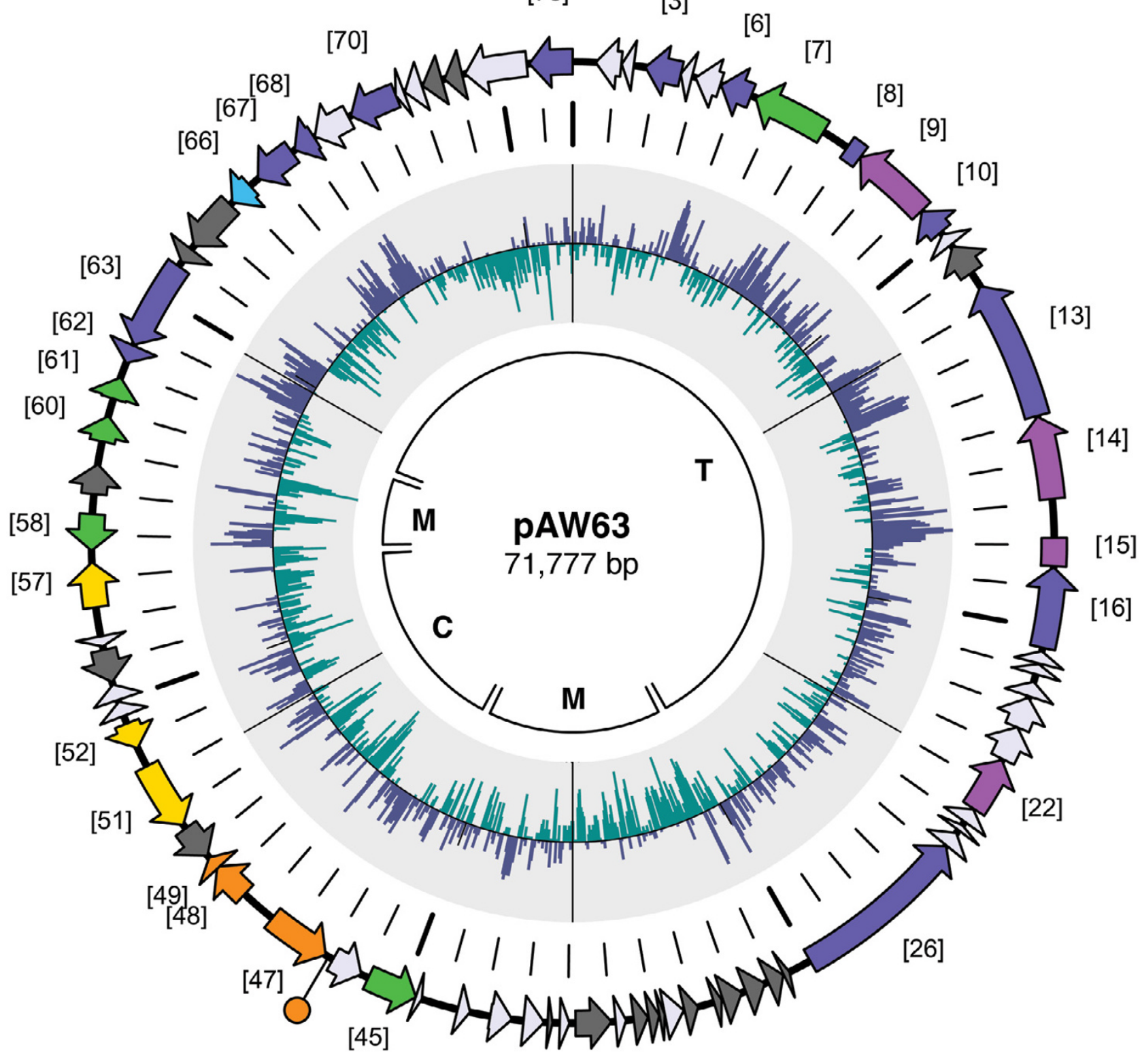

[45]

$\begin{array}{lll}\square \text { Replication } & \square \text { G+ conjugation } & \square \text { Mobile DNA }\end{array}$ Function unknown

Figure I

Circular map of pAW63. Coding Sequences (CDS) are represented by block arrows on the outer circle. Predicted functions/homologies are indicated by the color key featured below; numbers in brackets refer to main CDSs (see Table I for details). The first circle from the center delineates the functional modules identified on the plasmid; $\mathbf{T}$ indicates the transfer (tra) region, $\mathbf{C}$ indicates the control region (replication and regulation), and $\mathbf{M}$ indicates the two mobile DNA-associated flanking regions. The second circle from the center is a circular bar graph of the $\mathrm{G}+\mathrm{C}$ composition percentage of the plasmid sequence, with the overall mean value (33.8\%) as baseline; values above the line are $G+C$ rich (max value $5 \mathrm{I} \% \mathrm{G}+\mathrm{C})$ and values below the line are $A+T$ rich (min value $16 \% \mathrm{G}+\mathrm{C}$ ). The third circle from the center is a graduated size scale with small tick marks every I $\mathrm{kb}$ and large tick marks every $10 \mathrm{~kb}$. 
Table I: CDSs of pAW63: homologies and comparison with pXO2 and pBT9727

\begin{tabular}{|c|c|c|c|c|c|c|c|c|c|}
\hline \multirow{2}{*}{$\begin{array}{l}\text { pAW63 } \\
\text { CDS* }\end{array}$} & \multirow[t]{2}{*}{$\mathbf{s}$} & \multicolumn{2}{|c|}{ coordinates } & \multirow[t]{2}{*}{ size $(\mathrm{aa})$} & \multirow{2}{*}{$\begin{array}{l}\text { most relevant homology } \\
\text { function / microorganism / (amino acid identity percentage 'id \%') }\end{array}$} & \multicolumn{2}{|c|}{ pXO2 } & \multicolumn{2}{|c|}{ pBT9727 } \\
\hline & & start & stop & & & CDS* & id \% & CDS* & id $\%$ \\
\hline$\# 001$ & - & 1151 & 542 & 203 & - & $\# 001$ & $77 \%$ & \#001 & $67 \%$ \\
\hline$\# 002$ & - & 1450 & 1162 & 96 & hypothetical protein Efae0300 I I 29 Enterococcus faecium (29\%) & $\# 002$ & $55 \%$ & \#002 & $52 \%$ \\
\hline \#003 & - & 2585 & 1727 & 286 & chromosome segregation ATPase E. faecium (25\%) & $\# 004$ & $80 \%$ & \#003 & $67 \%$ \\
\hline \#004 & - & 2857 & 2581 & 92 & - & $\# 005$ & $92 \%$ & \#004 & $62 \%$ \\
\hline \#005 & - & 3554 & 2945 & 203 & - & $\# 006$ & $93 \%$ & \#006 & $60 \%$ \\
\hline \#006 & - & 4333 & 3577 & 252 & Tn9/6 ORF I4, similar to NLP/p60 family lipoprotein E. faecalis (37\%) & \#007 & $88 \%$ & \#007 & $78 \%$ \\
\hline \#007 & - & 6254 & 4448 & 602 & Type II intron reverse transcriptase lepA Bacillus megaterium (44\%) & - & - & - & - \\
\hline \#008 & - & 7314 & 6927 & 129 & Tn9/6 ORF I4, similar to NLP/p60 family lipoprotein E. faecalis (37\%) & $\# 007$ & $77 \%$ & \#007 & $61 \%$ \\
\hline \#009 & - & 9250 & 7315 & 645 & VirB4, Type IV secretory pathway E. faecium (37\%) & $\# 008$ & $95 \%$ & \#008 & $80 \%$ \\
\hline \#010 & - & 9935 & 9266 & 223 & ATPase involved in DNA repair E. faecium (30\%) & $\# 009$ & $91 \%$ & $\# 009$ & $75 \%$ \\
\hline \#0II & - & 10315 & 10000 & 105 & - & $\# 010$ & $95 \%$ & \#010 & $79 \%$ \\
\hline$\# 012$ & - & 11142 & 10377 & 255 & - & - & - & - & - \\
\hline$\# 013$ & - & 14900 & 11528 & 1124 & adhesin AidA, Type V secretory pathway E. faecium (25\%) & $\# 013$ & $74 \%$ & $\# 013$ & $48 \%$ \\
\hline$\# 014$ & - & 16905 & 14925 & 660 & VirD4, Type IV secretory pathway E. faecium (42\%) & $\# 014$ & $79 \%$ & $\# 014$ & $85 \%$ \\
\hline$\# 015$ & - & 18508 & 17839 & 223 & VirD4, Type IV secretory pathway E. faecium (38\%) & $\# 015$ & $94 \%$ & \#014 & $83 \%$ \\
\hline$\# 016$ & - & 20463 & 18534 & 643 & putative membrane protein (no bacterial homologs) & $\# 016$ & $65 \%$ & \#015 & $50 \%$ \\
\hline \#017 & - & 20847 & 20547 & 100 & - & $\# 017$ & $72 \%$ & \#016 & $43 \%$ \\
\hline$\# 018$ & - & 21116 & 20864 & 84 & - & $\# 018$ & $89 \%$ & $\# 017$ & $63 \%$ \\
\hline \#019 & - & 21662 & 21299 & 121 & hypothetical protein Listeria monocytogenes (37\%) & $\# 020$ & $83 \%$ & $\# 018$ & $58 \%$ \\
\hline \#020 & - & 22452 & 21702 & 250 & conserved hypothetical proteinL. monocytogenes (34\%) & $\# 021$ & $99 \%$ & \#019 & $70 \%$ \\
\hline$\# 021$ & - & 23282 & 22448 & 278 & conserved hypothetical proteinL. monocytogenes (32\%) & \#022 & $69 \%$ & \#020 & $61 \%$ \\
\hline \#022 & - & 24648 & 23316 & 444 & VirBI I, Type II/IV secretion system L. monocytogenes (35\%) & $\# 023$ & $87 \%$ & \#021 & $70 \%$ \\
\hline \#023 & - & 25024 & 24664 & 120 & conserved hypothetical protein L. monocytogenes $(37 \%)$ & \#024 & $94 \%$ & \#022 & $70 \%$ \\
\hline$\# 024$ & - & 25273 & 25123 & 50 & - & \#025 & $57 \%$ & - & - \\
\hline \#025 & - & 25735 & 25360 & 125 & - & \#026 & $77 \%$ & \#023 & $68 \%$ \\
\hline \#026 & - & 30002 & 25754 & 1416 & cell surface protein, similar to Rhs family Bacillus cereus (20\%) & $\# 027$ & $78 \%$ & \#024 & $84 \%$ \\
\hline$\# 027$ & - & 30709 & 30556 & 51 & - & - & - & - & - \\
\hline \#028 & - & 31117 & 30724 & $13 \mid$ & - & - & - & - & - \\
\hline \#029 & - & 31693 & 31204 & 163 & - & - & - & - & - \\
\hline$\# 030$ & - & 32268 & 31794 & 158 & - & - & - & - & - \\
\hline \#03। & - & 32492 & 32300 & 64 & - & - & - & - & - \\
\hline \#032 & - & 33216 & 32880 & 112 & - & - & - & - & - \\
\hline$\# 033$ & - & 33820 & 33694 & 42 & - & - & - & - & - \\
\hline$\# 034$ & - & 33693 & 33234 & 153 & - & - & - & \#026 & $58 \%$ \\
\hline \#035 & - & 34082 & 33827 & 85 & - & - & - & - & - \\
\hline \#036 & - & 34439 & 34100 & 113 & - & - & - & - & - \\
\hline \#037 & - & 34874 & 34622 & 84 & - & - & - & \#028 & $66 \%$ \\
\hline \#038 & - & 35824 & 34972 & 284 & - & - & - & - & - \\
\hline \#039 & - & 36199 & 35968 & 77 & - & - & - & \#033 & $50 \%$ \\
\hline$\# 040$ & - & 36488 & 36371 & 39 & - & - & - & - & - \\
\hline \#041 & - & 37060 & 36571 & 163 & - & $\# 031$ & $88 \%$ & \#034 & $39 \%$ \\
\hline$\# 042$ & - & $3786 I$ & 37336 & 175 & - & \#032 & $84 \%$ & \#036 & $50 \%$ \\
\hline$\# 043$ & - & 38649 & 38346 & 101 & - & $\# 033$ & $90 \%$ & \#037 & $60 \%$ \\
\hline$\# 044$ & - & 39688 & 39532 & 52 & - & \#034 & $66 \%$ & - & - \\
\hline \#045 & - & 40902 & 39684 & 406 & prophage helix-turn-helix protein Bacillus cereus G924I (25\%) & $\# 036$ & $89 \%$ & \#038 & $59 \%$ \\
\hline \#046 & - & 41848 & 41089 & 253 & - & \#038 & $88 \%$ & \#045 & $70 \%$ \\
\hline \#047 & - & 43592 & 42050 & 514 & replication protein RepE E. faecalis (40\%) & \#039 & $96 \%$ & \#046 & $83 \%$ \\
\hline$\# 048$ & + & 44458 & 45385 & 309 & replication-associated protein RepB E. faecalis & - & - & - & - \\
\hline \#049 & + & 45347 & 45671 & 108 & putative replication-associated (no homologies) (31\%) & - & - & - & - \\
\hline \#050 & - & 46557 & 45735 & 274 & - & - & - & - & - \\
\hline$\# 051$ & - & 48301 & 46663 & 546 & pheromone binding protein B. cereus G924I (73\%) & \#089 & $90 \%$ & \#055 & $80 \%$ \\
\hline \#052 & - & 49424 & 48788 & 212 & DNA-binding protein B. cereus G924I (53\%) & \#093 & $61 \%$ & \#059 & $77 \%$ \\
\hline$\# 053$ & + & 49620 & 49968 & 116 & conserved hypothetical protein Staphylococcus aureus (31\%) & \#095 & $75 \%$ & \#062 & $71 \%$ \\
\hline$\# 054$ & + & 50020 & 50407 & 129 & group specific protein B. cereus ZK $(75 \%)$ & \#096 & $77 \%$ & \#063 & $76 \%$ \\
\hline \#055 & - & 51260 & 50471 & 263 & hypothetical protein IpII 076 Legionella pneumophila (49\%) & - & - & - & - \\
\hline \#056 & - & 51589 & 51343 & 82 & hypothetical protein B. cereus ATCC I $4579(60 \%)$ & - & $86 \%$ & - & - \\
\hline \#057 & + & 52288 & 53362 & 358 & RapD response regulator $B$. thuringiensis $(94 \%)$ & - & - & - & - \\
\hline \#058 & - & 54506 & 53636 & 290 & transposase, IS5 family Aneurinibacillus thermoaerophilus (52\%) & - & - & - & - \\
\hline
\end{tabular}


Table I: CDSs of pAW63: homologies and comparison with pXO2 and pBT9727 (Continued)

\begin{tabular}{|c|c|c|c|c|c|c|c|c|c|}
\hline$\# 059$ & + & 54988 & 55699 & 237 & - & - & - & - & - \\
\hline \#060 & + & 56252 & 56870 & 206 & site-specific recombinase, resolvase Clostridium thermocellum (54\%) & - & - & \#065 & $69 \%$ \\
\hline \#061 & + & 57303 & 57834 & 177 & phage site-specific recombinase B. cereus ATCC $14579(64 \%)$ & $\# 101$ & - & \#066 & $73 \%$ \\
\hline \#062 & - & 58650 & 58203 & 149 & CAAX N-terminal protease B. cereus ATCC I 4579 (35\%) & \#103 & - & \#07l & $68 \%$ \\
\hline \#063 & - & 60821 & 58679 & $7 \mid 4$ & DNA topoisomerase, Trsl/Tral Lactococcus lactis (45\%) & \#104 & - & \#072 & $74 \%$ \\
\hline \#064 & - & 61323 & 60942 & 127 & - & - & - & - & - \\
\hline$\# 065$ & - & 62731 & 61429 & 434 & conserved hypothetical protein B. cereus G924I (35\%) & - & - & - & - \\
\hline \#066 & - & 63383 & 62798 & 195 & AbiQ abortive infection mechanism L. lactis (34\%) & - & - & \#073 & $28 \%$ \\
\hline \#067 & - & 64659 & 63633 & 342 & signal transduction histidine kinase $E$. faecium (38\%) & \#107 & $90 \%$ & \#074 & $83 \%$ \\
\hline \#068 & - & 65290 & 64738 & 184 & putative membrane-bound hydrolase Bacillus licheniformis (32\%) & \#109 & - & $\# 075$ & $92 \%$ \\
\hline \#069 & - & 66240 & 65313 & 309 & - & $\# 110$ & $83 \%$ & \#076 & $60 \%$ \\
\hline \#070 & - & 67475 & 66302 & 391 & ATPase involved in DNA repair E. faecium (42\%) & $\#$ \# I I & $77 \%$ & \#077 & $94 \%$ \\
\hline \#071 & - & 67681 & 67471 & 70 & - & $\# 112$ & $62 \%$ & \#078 & $75 \%$ \\
\hline \#072 & - & 68132 & 67703 & 143 & - & $\# 113$ & $80 \%$ & \#079 & $69 \%$ \\
\hline \#073 & - & 68628 & 68151 & 159 & - & - & - & - & - \\
\hline \#074 & - & 69124 & 68695 & 143 & - & - & - & - & - \\
\hline \#075 & - & 70679 & 69197 & 494 & - & - & $49 \%$ & \#079 & $50 \%$ \\
\hline \#076 & - & 71773 & 70744 & 343 & ATPase involved in DNA repair E. faecium (36\%) & - & $96 \%$ & \#080 & $83 \%$ \\
\hline
\end{tabular}

* CDS numbers are abbreviated forms originating from their formal designations: pAW63-\#\#, GBAA_PXO2_0\#\#, PBT9727_0\#\#\#

\section{Replication and regulatory functions are grouped in an 8 kb 'control center'}

All the elements that were putatively identified as being directly involved in plasmid replication, copy control or other regulatory processes were found to reside within an $8 \mathrm{~kb}$ region of the plasmid containing 12 CDSs (CDS 46 to 57), of which 6 could not be assigned to a functional category. This region was delineated by mobile genetic elements or remnants thereof, and contained five of the eight CDSs that were found in clockwise orientation, the other three being located in its gene mobility-associated flanking sequences.

The $4.1 \mathrm{~kb}$ replicon of pAW63 was characterized in a previous study [18] and classified as belonging to the pAM $\beta 1$ family of theta-replicating conjugative plasmids, with which it shares a similar cis-functioning origin of replication (ori). The largest of the four CDSs contained in this region, Rep63A (CDS 47), displayed strong similarity to the replication proteins of several plasmids in this family, as well as $96 \%$ amino acid identity with the RepS protein of the pXO2 replicon [18]. Rep63B, the second largest CDS of the replicon (CDS 48), displayed strong similarity with copy control proteins RepB and PrgP from the Enterococcus faecalis conjugative plasmids pAD1 [22] and pCF10 [23], respectively [18]. Although the two smaller CDSs (49 and 50) did not display any significant homologies, the authors noted that one of these, CDS 49, showed properties (location, size, orientation and hydrophilicity) that likened it to $r e p C$ and $p r g O$, which are putative genes encoding stability functions on pAD1 and pCF10, respectively.
Upon further sequencing of the plasmid, three additional putative regulatory elements were identified in close proximity to the replicon. These elements (CDS 51, 52 and 57) were homologs of genes that are highly conserved throughout the $B$. cereus group as well as in some less closely related species. CDS 51 and 52 displayed significant homologies to an oligopeptide $\mathrm{ABC}$ transporter functioning as a pheromone binding protein, and to a DNAbinding protein, respectively. The clockwise-oriented CDS 57 showed a distinctly low overall $\mathrm{G}+\mathrm{C}$ content and was found to encode a protein with $94 \%$ identity to RapD, a response regulator aspartate phosphatase acting as a transcriptional activator involved in the regulation of sporulation [24].

\section{The conjugative functions of pAW63 are grouped in a 42 kb tra region}

All 15 CDSs assigned putative conjugative functions were found to be located within a $42 \mathrm{~kb}$ region of the plasmid (CDS 1 to 26 and 62 to 76 ; hereafter referred to as the tra region). Every one of the 41 CDSs predicted within this region was in the same counter-clockwise orientation, suggesting an operon-style transcription scheme may be in place, which would be consistent with the genetic organization of most known conjugative systems [25].

\section{pAW63 encodes three homologs of Gram-negative T4SS components}

Three CDSs were found to encode proteins with significant similarity to components of the Vir secretion system, originally characterized in Agrobacterium tumefaciens, which is the archetypal model for the Type IV Secretion System (T4SS) that is believed to carry out the conjugative process in Gram-negative bacteria, as recently reviewed 
$[8,26]$. Briefly, the T4SS can be summarized as a two-step mechanism [27] which involves the replication of the plasmid DNA by effector proteins followed by the translocation of a single-stranded molecule across the cell envelope into the recipient cell. The transfer is powered by the action of a molecular pump and the DNA is thought to travel through a channel formed by a core protein complex, while the necessary close cell-to-cell contact is mediated by surface structures.

Analysis of the pAW63 sequence (Fig. 1) showed that CDSs 14 and 15 were in fact the two halves of an interrupted CDS encoding a homolog of the VirD4 component, which has been shown to function as a coupling protein between the DNA strand replication machinery and the transmembrane transfer complex and powerhouse. Interestingly, the $935 \mathrm{bp}$ space between them was found to be completely devoid of coding sequences and showed a distinctly higher $\mathrm{G}+\mathrm{C}$ content than was considered average for the rest of the plasmid. CDS 9 displayed $37 \%$ identity with VirB4, a membrane associated N-triphosphatase which is thought to play a role in providing the energy needed to power the actual DNA transfer. CDS 22 displayed 35\% identity to VirB11, a subunit implicated in both Type II and Type IV secretion systems that was shown to be necessary for conjugation, although its exact role remains unclear. Structural analyses have shown it to possess a transmembrane domain as well as an ATPase domain, and recent research suggests that the subunits are arranged as a dynamic hexameric assembly associated with the inner membrane and functioning as a gating component [28].

\section{pAW63 encodes homologs to components of Gram-positive conjugation systems from diverse species}

Another 10 CDSs were classified as conjugative on the basis of their homologies, this time to genes from Grampositive conjugation systems. Most notably, CDS 63 showed a distinctly high $\mathrm{G}+\mathrm{C}$ content and was found to encode a topoisomerase displaying $45 \%$ identity to the TrsI/TraI protein from the Lactococcus lactis conjugative plasmid pMRC01 [12]. This component of the lactococcal conjugative system is thought to function as a relaxase, a role equivalent to that of VirD2 in the T4SS machinery.

CDSs 67 and 70 both displayed significant homology to LtrC-like (from the Lactococcal transfer ORF $\underline{\text { C) putative }}$ conjugative elements from Streptococcus, Staphylococcus, Lactococcus and Listeria species (with an average 30\% identity), although they had different 'most relevant BLAST hits', as shown in Table 1. The function of the LtrC element itself, which was identified in the tra region of the lactococcal conjugative plasmid pRS01 [29], has not yet been determined.
CDSs 6 and 8 were predicted to be the two halves of an interrupted protein with significant resemblance to ORF 14 from the enterococcal conjugative transposon Tn916, a self-transmissible molecule encoding tetracycline resistance [30]. The function of Tn916 CDS 14 has not yet been elucidated, but further results of the similarity search displaying comparable identity levels included a soluble lytic murein transglycosylase from E. faecium as well as the invasion-associated extracellular protein Iap from $L$. monocytogenes.

Furthermore, three CDSs (CDS 13, 16 and 26) were predicted to encode proteins that may be involved in the establishment of intimate cell-to-cell contact, either as aggregation substances secreted into the medium, or as cell surface determinants. CDS 13 showed a distinctly high $\mathrm{G}+\mathrm{C}$ content in its second half, which contained two tracts of distinct repeated units that were predicted to correspond to a series of helix-turn-helix motifs followed by a series of pleated sheets in the protein product. It also displayed 25\% identity with the adhesin AidA from the Type $\mathrm{V}$ secretory pathway of E. faecium, which relies on an autotransporter system for cytolysin secretion. The adhesin itself is primarily implicated in the pheromonemediated enterococcal mating process as an aggregation substance, but it has also been shown to act as an adhesion factor in the course of infection of eukaryotic cells by pathogenic E. faecalis strains and as such it may be considered a virulence determinant [31]. CDS 26 was the largest CDS found on the plasmid (4.2 kb) and showed little significant resemblance to any known sequences except for a positive match ( $20 \%$ identity) with a $3.3 \mathrm{~kb}$ long cell-surface protein from the $B$. cereus reference strain ATCC14579 and another (23\% identity) with a $2.37 \mathrm{~kb}$ long Rhs family protein (for Recombination hot spot) from Bifidobacterium longum. Rhs products are thought to possess properties typical of cell surface proteins and often present internal rearrangements that lead to antigenic variation [32]. CDS 16 was unlike any known bacterial sequences (apart from those of plasmids pBT9727 and pXO2) but the putative 643 residue protein was predicted to have a secondary structure consisting essentially of hydrophilic helices, suggesting it may function as a surface-associated or free-acting aggregation substance.

Finally, the remaining CDSs correspond to ATPases predicted to be involved in segregation and DNA repair (CDSs 3, 10, 62 and 76), as well as a predicted membranebound hydrolase (CDS 68).

\section{pAW63 and mobile genetic elements}

Five CDSs were readily identified as mobile genetic elements on the basis of their homologies. Standing apart from the other four by both character and location, CDS 7 was found positioned right between the two fragments 
of the interrupted Tn916 ORF 14-like element and displaying $44 \%$ identity to IepA, a group II intron-encoded protein from Bacillus megaterium which further BLAST results revealed to be a reverse transcriptase and maturase. This immediately led to the conclusion that CDS 7 was part of a group II intron that had inserted itself in the uninterrupted ancestor of CDSs 6 and 8, a finding supported by the skewed $\mathrm{G}+\mathrm{C}$ content profile corresponding to the site of the proposed insertion. The element was tentatively named B.th.I1 (for $\underline{B}$. thuringiensis $\underline{I}$ tron \# $\underline{1}$ ). Furthermore, a closer examination of the 935 bp fragment of seemingly non-coding DNA with high $\mathrm{G}+\mathrm{C}$ content found interrupting the VirD4 homolog (CDSs 14 and 15) revealed that the extremities of this insert were nearly identical to those of the B.th.I1 intron mentioned above, indicating the presence in this locus of a second retroelement presumably derived from the first. This second element was tentatively named B.th.I2 (for $\underline{B}$. thuringiensis

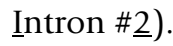

Three other of these CDSs (CDS 58, 60 and 61) were found in close proximity to each other by the regulation side of the proposed 'control center' region, as mentioned previously, and were predicted to encode various types of DNA recombinases.

Finally, CDS 45 was found flanking the replication side of the replication control center and showing similarity to a prophage helix-turn-helix protein from the $B$. cereus strains G9241 and ATCC 14579 . The $10 \mathrm{~kb}$ region downstream of CDS 45 was found to encode 18 rather short CDSs ( $\approx 300$ bp on average) with no significant homologies in a configuration reminiscent of typical bacteriophage gene structure, which may correspond to a prophage integrated within the plasmid sequence. Intriguingly, while the first $4 \mathrm{~kb}$ of this region showed a $\mathrm{G}+\mathrm{C}$ content in accordance with the rest of the plasmid, the following $6 \mathrm{~kb}$ segment showed a distinctly low $\mathrm{G}+\mathrm{C}$ content along most of its length.

As a counterpoint to the considerable amount of phagederived genetic material tentatively identified on the plasmid, CDS 66 displayed significant similarity to AbiQ, a single-protein abortive infection mechanism from L. lactis which limits phage dissemination by shutting down the lytic cycle and leading the infected host cells to their death [33].

\section{pAW63 shares a common backbone with pXO2 from B.} anthracis and $p B T 9727$ from $B$. thuringiensis konkukian Similarities between pAW63 and the virulence plasmid pXO2 from $B$. anthracis had been observed previously $[18,20]$ and further investigation (C. Kuske, pers. comm.) had yielded thirty short sequences (400 bp long on average) corresponding to regions of pAW63 which had been shown to hybridize to $\mathrm{pXO} 2$. This data was used in this study as the basis for the sequencing of pAW63, in a strategy that involved the outlining of a backbone sequence from which primers pairs were designed to amplify and individually sequence the intervening regions.

These premises had guaranteed at least several hits to the virulence plasmid from $B$. anthracis, $\mathrm{pXO} 2$, and the final sequence of pAW63 certainly did not disappoint. Indeed, a preliminary alignment of their sequences showed that aside from a $37-\mathrm{kb}$ region found only on $\mathrm{pXO} 2$ corresponding to the region containing the anthrax capsule genes and associated regulatory elements, they possessed a highly similar genetic makeup. Furthermore, the BLAST results had also revealed the existence of a third closely related plasmid, pBT9727, which was recently published along with the genome sequence of its host strain B. thuringiensis serovar konkukian strain 97-27 [GenBank:NC_005957] and shows a comparable overall gene organization and coding content to that of the other two. These findings were consolidated by performing a BLAST Score Ratio Analysis of the predicted proteomes of the three plasmids, the results of which indicated a high level of synteny, with the pAW63 and pBT9727 pair showing the highest ratio of shared CDSs although the associated identity percentages were the poorest. Regarding the CDSs shared by each of these plasmids with pXO2, pBT9727 possessed the highest number of these but for the most part pAW63 showed higher identity percentages (Tables 1 and 2). A global phylogenetic analysis was performed on the three proteomes by systematically aligning the 42 homologous predicted proteins shared by all three plasmids together along with their most relevant common BLAST hit result and building a tree from the four sequences (data not shown). Results were consistent for all quartets examined and suggested that pBT9727 had been the first to branch off from the common ancestor, while pAW63 and pXO2 diverged later. The detailed alignment of the three sequences shown in Figure 2 clearly illustrates the extent of the synteny observed between these plasmids.

\section{The tra region of pAW63 finds its equivalent on both pXO2 and PBT9727, with high levels of identity and contrasting discrete variations}

Both pXO2 and pBT9727 were found to possess an approximately $42 \mathrm{~kb}$ long region that was almost identical to the tra region of pAW63 with respect to gene structure and organization, as illustrated in Fig. 2. All of the CDSs identified on pAW63 as possible conjugative genes were found to have highly similar homologs on both of these plasmids (see percentages in Tables 1 and 2), although several displayed key differences as detailed below. 


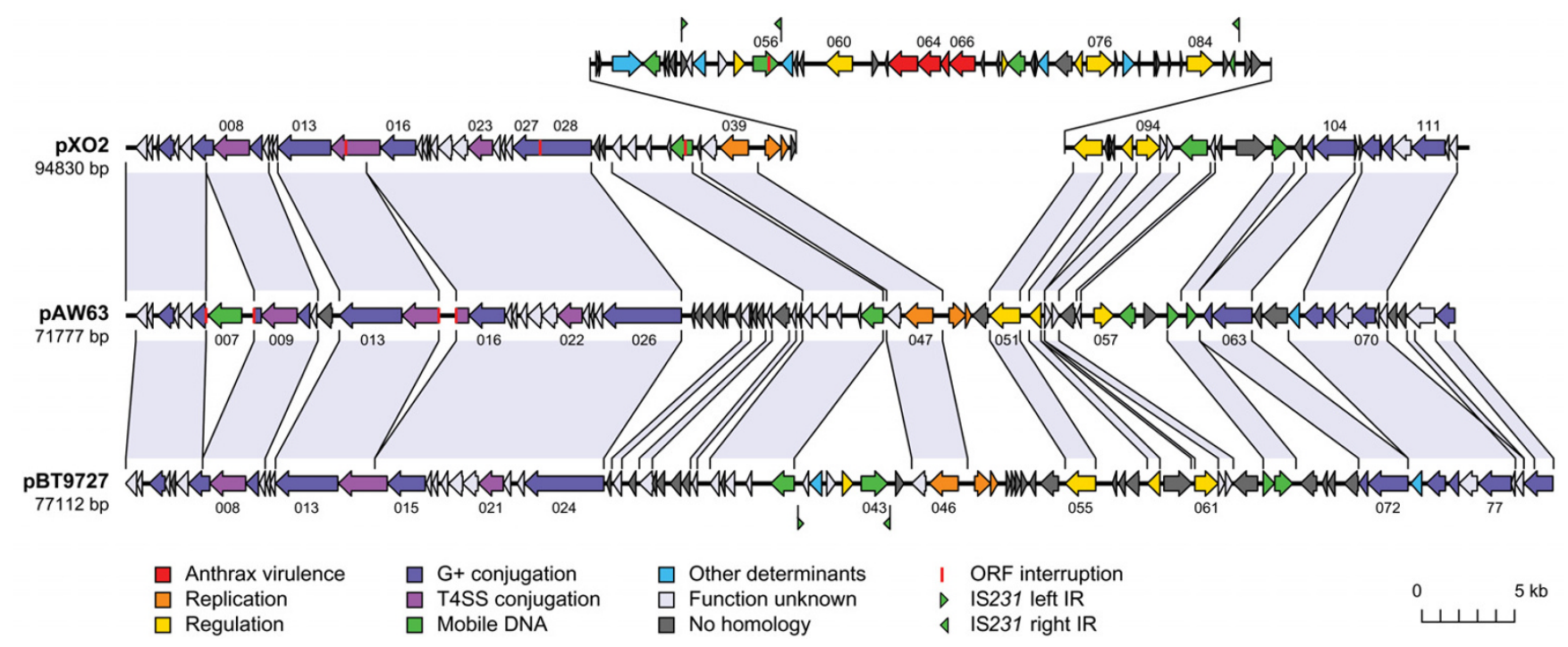

\section{Figure 2}

Linear alignment of pXO2, pAW63 and pBT9727. CDSs are represented by block arrows. Several CDS numbers (see Table I) are indicated for reference on each plasmid, just above or below their representation. Predicted functions/homologies are indicated by the color key featured below. Well conserved segments of the plasmids are paired by shaded regions $(>40 \%$ amino acid identity); percentages for specific CDS pairs can be found in Tables I and 2. The proposed PAI of pXO2 is raised above the rest of the sequence for clarity. Scale is indicated by the bar in the lower right-hand corner.

Table 2: Comparison of pXO2 and pBT9727 CDSs with no homologs on pAW63

\begin{tabular}{|c|c|c|c|}
\hline B. anthracis CDS & id \% & B.t. konkukian CDS & Putative gene functions \\
\hline GBAA_PXO2_001I & $65 \%$ & pBT9727_001 I & - \\
\hline GBAA_PXO2_0012 & $60 \%$ & pBT9727_0012 & - \\
\hline GBAA_PXO2_0028 & $67 \%$ & pBT9727_0024 & - \\
\hline GBAA_PXO2_0035 & $64 \%$ & pBT9727_0038 & - \\
\hline GBAA_PXO2_0040 & $91 \%$ & pBT9727_0047 & replication-associated protein \\
\hline GBAA_PXO2_004I & $79 \%$ & pBT9727_0048 & replication-associated protein \\
\hline GBAA_PXO2_0052 & $89 \%$ & pBT9727_0039 & - \\
\hline GBAA_PXO2_0053 & $72 \%$ & pBT9727_0040 & CAAX $\mathrm{N}$-terminal protease \\
\hline GBAA_PXO2_0054 & $92 \%$ & pBT9727_004I & - \\
\hline GBAA_PXO2_0055 & $97 \%$ & pBT9727_0042 & transcriptional regulator TetR \\
\hline GBAA_PXO2_0056 & $96 \%$ & pBT9727_0043 & IS23 I transposase \\
\hline GBAA_PXO2_0057 & $66 \%$ & genomic? & bacitracin transport permease \\
\hline GBAA_PXO2_006I & $39 \%$ & genomic? & - \\
\hline GBAA_PXO2_0075 & $36 \%$ & genomic? & sensor histidine kinase \\
\hline GBAA_PXO2_0086 & $81 \%$ & pBT9727_0043 & IS23I transposase \\
\hline GBAA_PXO2_0094 & $93 \%$ & pBT9727_006I & DNA-damage repair protein \\
\hline
\end{tabular}

While the copy of the Tn916 CDS 14-like element present on pAW63 had been found to be encoded by two CDSs (CDSs 6 and 8) due to the insertion of the group II intron B.th.I1 (see above), the corresponding homologs of this element were uninterrupted on pBT9727 and pXO2. The sequence comparison of these 'native' versions of the gene with the one containing the intron allowed for the precise site of insertion to be determined. This region of the Tn916 CDS 14-like element was then aligned with its closest homologs as identified by BLAST search, revealing that the insertion had taken place in a relatively well-conserved domain of the gene. This is consistent with the 
observation that group II introns target specific genes or gene domains [34] despite the lack of experimental data available concerning the insertion of this particular element.

Similarly, the three plasmids possessed separate versions of the VirD4 homolog. The CDS encoding this gene was found to be interrupted in a distinct manner on both pXO2 and pAW63, while it appeared to be intact on pBT9727. As indicated previously, the pAW63-borne homolog (CDS 14 and 15) was interrupted by the putative ORF-less group II intron B.th.I2, while the cause of the disruption of the pXO2-borne homolog was a frameshift due to the deletion of two nucleotides in a C-rich stretch located at two-thirds of the original protein.

Likewise, homologs for the putative cell-surface protein encoded by CDS 26 of pAW63 were found on both pXO2 and pBT972, albeit in two different forms. While pBT9727 was found to possess a presumably intact version of the gene, the pXO2-borne version appeared to be disrupted by a single nucleotide deletion causing a frameshift twothirds into the original protein. This was confirmed to be a genuine feature and not a sequencing artifact by comparing the three available sequences of pXO2 [GenBank:NC_002146, GenBank:NC_007323, GenBank:NC_003981] which had identical frameshifts in the corresponding locus.

Finally, the three homologs of the putative adhesin (CDS 13 on pAW63) were found to differ in a very interesting way. While the first half of the protein was well conserved in all three versions, the second half containing the repeated motifs was almost identical between $\mathrm{pXO} 2$ and pAW63, although pXO2 lacked several repetitions of the basic units, and pBT9727 possessed completely different basic units which nevertheless gave rise to highly similar secondary structure predictions.

\section{Sequence variability is highest in the replication control center area and is associated with the presence of multiple mobile genetic elements}

The mobile DNA-based borders of the replication control center of each plasmid were found to be comparable as follows. The putative prophage structure bordering the replicon (CDS 27 to 45 on pAW63) was found on all three plasmids, although the second part of this structure was poorly conserved, to the point of being absent from $\mathrm{pXO} 2$. The other side of this region was delineated in all three cases by variants of the site-specific recombinase found on pAW63 (CDS 61). The area between the replicon and this recombinase was highly variable between the three plasmids, with pAW63 featuring the most CDSs therein (CDS 50 to 60).
Regarding the regulatory elements present in this region, it was observed that while both the putative pheromone receptor (CDS 51) and the DNA-binding protein (CDS 52) identified on pAW63 were also present as close homologs on the two other plasmids, the putative transcriptional activator RapD (CDS 57) was not found in any form on either of them. On the other hand, both pBT9727 and $\mathrm{pXO} 2$ were found to possess almost identical copies of two other genes that were not present on pAW63: a homolog of the DNA-damage repair gene uvr from B. subtilis, and the gene encoding the transcriptional activator TetR.

\section{A recent recombination event caused $p A W 63$ to exchange part of its replicon}

It is interesting to note that while the origin of replication and main replication protein Rep63A (CDS 47) were found to be highly conserved across all three plasmids, no homologs were found for the two other replication-associated CDSs of pAW63 (CDS 48 and 49), but two CDSs of similar size and orientation were found in equivalent locations relative to the common backbone on each of the other two plasmids, suggesting they share a functional homology with the two pAW63 CDSs, despite their lack of sequence similarity. Furthermore, these pBT9727- and pXO2-borne pairs of CDSs were found to share a high level of sequence identity with each other, suggesting that the original corresponding part of the pAW63 replicon had been exchanged for its present form at some point following the divergence of pXO2 and pAW63. In support of this idea, a similar pattern of resemblance/difference was observed for a series of partially palindromic iterons present in the vicinity of the replication genes which were previously believed to be implicated in the replication process. While the iteron sequences found on pBT9727 and $\mathrm{pXO} 2$ were by no means identical, they did share similar repeated motifs that were completely different from those identified on pAW63. The discovery of further repetitions of these various motifs as well as several additional palindromes in key locations of the sequence have led to the elucidation of a complex structure of palindromic and/or iterative elements serving as node points for recombination events that may have been responsible for major divergences in synteny between the three plasmids in the replicon area, as illustrated in Figure 3.

\section{Comparative evidence supports the existence of a $37 \mathbf{k b}$ pathogenicity island (PAI) on pXO2}

The $37 \mathrm{~kb}$ region of DNA located after the replicon on pXO2 was found to exhibit most of the characteristics of a bacterial pathogenicity island (PAI) as defined by Hacker and Kaper [35]. All of the genes carried by pXO2 that are known to play a capital role in the course of anthrax infection, such as the capsule genes, were clustered in this region, along with the regulatory genes $a c p A$ and $a c p B$, 


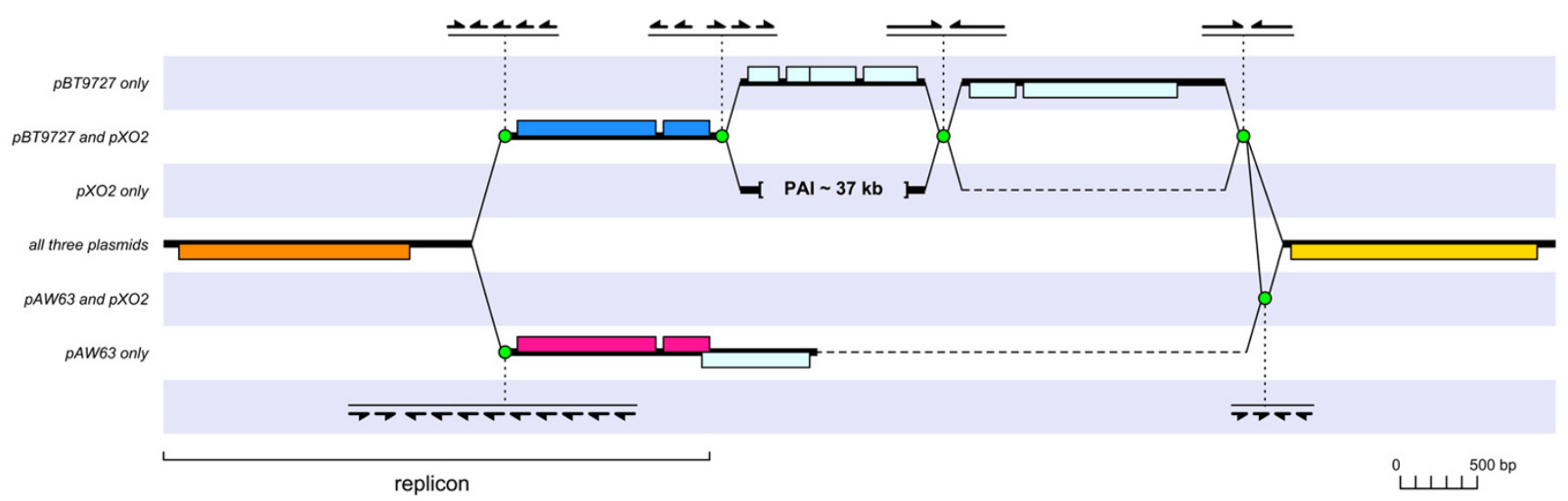

Figure 3

Relational diagram of the replicon region of the three plasmids. Comparison of the replicon region of each plasmid reveals a complex structure of palindromic and/or iterative elements serving as node points for recombination events. Sequence segments are represented by thick horizontal lines joined by solid diagonal lines. The background striping highlights 'shared' versus 'unique' sequence segments as indicated by the text legend on the left hand side. Horizontal dashes are spacers to indicate a shorter length or lack of corresponding segment. Node points putatively involved in recombination events are represented by green circles; iterative and/or palindromic sequence units by half arrows; CDSs by rectangles, above the sequence line to indicate clockwise orientation, or below to indicate counter- clockwise orientation.

which are directly associated with their expression during the development of the pathology [36]. Furthermore, this region had distinctive genetic properties from the rest of the plasmid, such as a lower $\mathrm{G}+\mathrm{C}$ content (30.9\% against $34.3 \%)$, and more variation in the orientation and phase of coding sequences. It was also found to be rich in mobile genetic elements (some cryptic or defective), such as multiple inactivated copies of the IS231 transposase $[16,37]$ and a vestigial class II transposon.

The comparison of the sequences flanking the proposed PAI on pXO2 and their equivalents on pAW63 and pBT9727, as described above (Fig. 3), revealed the existence of specific nodes consisting of iterative and/or palindromic sequences that could be held responsible for the acquisition of the PAI region through a past recombination event, though not excluding the possibility of later rearrangements having taken place within this region.

\section{pXO2 and pBT9727 possess copies of Insertion Sequence IS23 I $L$ in different loci, causing a visible interruption in synteny}

The results of the three-way BLAST Score Ratio Analysis of this complex plasmid trio highlighted a group of five CDSs that were not present on the pAW63 sequence itself but were shared with a high degree of similarity between pBT9727 and pXO2. Their location was different on either plasmid with respect to the common backbone, thus representing a significant interruption in the synteny of the plasmids. It appeared that this small group had been previously described on pXO2 as an IS231-derived [38] Insertion Sequence (IS) and designated IS231L [37], although it was assumed to be incapable of autonomous transposition due to a frameshift in the CDS encoding the transposase. However, the copy of the IS231L element harboured by pBT9727 was found to have an uninterrupted and therefore supposedly functional transposase, as well as nearly perfect Inverted Repeats (IR), the canonical $20 \mathrm{bp}$ boundaries of this type of mobile element matching those of the pXO2-borne IS231L element.

Interestingly, the copy of IS231L found on pBT9727 was found to be nested within the Tn1546-related [39] left IR of a novel Class II transposon belonging to the Tn3 family, encoding a single cryptic CDS and tentatively named TnBt9727. Likewise, the pXO2-borne copy of IS231L was nested within the TnARS1-related [GenBank AY780525] right IR of a vestigial class II transposon. No corresponding left IR was found for this element, but an IS3 family transposase was found in close proximity to the putative right IR, suggesting a possible structural association.

Furthermore, the presence of two other CDSs with homology to the IS231 transposase in the PAI of pXO2 prompted a search for other instances of IRs matching those of IS231L in the vicinity of these CDSs. A well-conserved copy of the right IR was indeed discovered near the 
end of the PAI beside a second CDS encoding an IS231 transposase-like gene (Fig. 2).

\section{Discussion}

A large proportion of the pAW63 sequence was observed to possess significant similarity to plasmids originating from several different bacterial species harbouring fundamentally different conjugative and replication systems. The resulting hybrid combination of genes probably opens up the mating scope of the plasmid. The physical arrangement of the plasmid was identified as a composite structure consisting of a $42 \mathrm{~kb}$ tra region encoding conjugation functions, organised in typical operon fashion, and an $8 \mathrm{~kb}$ control center encoding the replication and regulation functions, joined by mobile genetic elements or remains thereof (Fig. 1).

Analysis of the replication control center of pAW63 revealed that it possessed copy control proteins similar to those found on the enterococcal conjugative pheromone plasmids pAD1 and pCF10. However, pAW63 conjugative transfer among $B$. thuringiensis strains has been shown to be independent from recipient-encoded pheromones [15]. It has been suggested that in addition to their role in the transfer process, host-produced pheromones may play a role in the replication of the pAD1 and pCF10 plasmids [23]. Given a similar copy control mechanism, the apparent independence of pAW63 from pheromone signalling may account for the greater host range of pAW63 compared to pAD1 and pCF10, by removing the requirement for a compatible pheromone system in the recipient mating partner. It was therefore very interesting to find near the pAW63 replicon two CDSs respectively encoding an $\mathrm{ABC}$ transporter-type pheromone receptor, homologous to those found in Enterococcus and Listeria species, and a close homolog of RapD, a transcriptional activator from B. thuringiensis serovar morrisoni. At this point it is unclear whether the function of these elements is restricted to either the plasmid copy control or the regulation of conjugation, or whether these processes are directly linked by common regulatory pathway components. Nonetheless, the presence of a putative pheromone-sensing mechanism on pAW63 suggests that the conjugative transfer process of the plasmid may follow alternate or optionally additive regulatory pathways depending on the species of the mating cells.

Regarding basic conjugative function, the presence on the plasmid of genes related to the T4SS system corroborates similar findings [40] concerning the transfer system of the streptococcal plasmid pIP501, which bears a tra region containing VirD4, VirB4 and Vir B11 homologs. Interestingly, all three of the pAW63 and pIP501 T4SS-like proteins correspond to components of the system that operate within the cell or in association with the inner membrane to prepare the plasmid DNA for transfer and provide motor function, and no homologs have been found on the plasmid to the 'outer' components. This could be explained by the idea that the inner part of the Gram-positive cell wall structure is sufficiently similar to that of the Gram-negative hosts for some of the 'inner' components, designated as effector and transporter molecules, of both transfer systems to share their main characteristics and possibly a common evolutionary history derived from replication mechanisms. Conversely, it seems reasonable to assume that major differences in the cell wall structure and composition, such as the presence of a thick peptidoglycan layer and the absence of an outer membrane, would be mirrored by the presence of specific protein components responsible for the 'external' steps of the conjugative process. This includes sensing of recipients, cell to cell attachment and the bridging of cell walls to effect DNA transfer, and requires the assembly of a core complex as well as cell surface structures. With respect to the latter, several putative cell surface- or membrane-associated proteins, such as the adhesin encoded by CDS 13 and the very large protein encoded by CDS 26, have already been identified in the tra region of pAW63, although further studies will be necessary to work out their specific roles in the conjugative process.

The presence of introns B.th.I1 and B.th.I2 within two genes of which at least one (the VirD4 homolog) may be considered essential to the conjugative process, poses the question of the functionality of the interrupted genes, as well as that of possible collateral effects caused by these elements. Regarding maintenance of functionality of the host genes, current models of group II intron splicing as well as experimental research show that intron excision during transcription leads to the production of a complete and functional protein [41]. In addition, this type of mobile element is thought to insert preferentially into certain conjugative genes such as relaxases, and it has been suggested that such an insertion actually enhances the efficiency of the conjugative system [34,42]. Furthermore, the relationship between B.th.I1, which encodes its own reverse transcriptase, and B.th.I2, which does not, deserves further investigation. While such a configuration has rarely been observed among eubacteria, ORF-less introns that were closely related to an intron encoding a reverse transcriptase located in the same genome have been identified in cyanobacteria and archeae [43]. It has been proposed that these CDS-less elements were derivatives of their 'complete' RT-encoding relatives [44]. Significantly, several of these 'degenerate' elements were shown to be mobile, raising the possibility that mobility may be supplied in trans [41] as is the case for the Mobile Insertion Cassette MIC231 trans-activated by IS231 transposase $[37,45]$. 
The comparison of the tra regions of pAW63, pBT9727 and $\mathrm{pXO} 2$ has provided several valuable indications on the relative importance of specific genes in the conjugative process. While pAW63 is known to be fully functional and quite efficient as a conjugative plasmid, $\mathrm{pXO} 2$ is believed to be incapable of autonomous transfer although it has been shown to be mobilizable by the conjugative plasmid pXO14 from B. thuringiensis toumanoffi [46], suggesting that $\mathrm{pXO} 2$ carries a set of conjugative genes that is incomplete or disrupted in one or several key components. Both pXO2 and the newly sequenced plasmid pBT9727 were now shown to possess a set of potential conjugation genes closely related to those of pAW63. The transfer capabilities of pBT9727 have not yet been assayed, but its sequence features point towards partial conjugative function at the very least, and possibly full self-transmissibility. For these reasons, further studies will focus on loci exhibiting discrete variations in order to expose their specific contribution to the transfer process. For instance, the unique interruptions found in the $\mathrm{pXO} 2$ homolog of the VirD4 element and in that of the putative cell surface protein encoded by CDS 26 on pAW63 may prove to be particularly significant, especially if pBT9727 is shown to be fully conjugative.

From a broader point of view, the combination of the phylogenetic analysis of the three proteomes with the elucidation of the structural features delineating the major sequence differences in the replication control center has made it possible to roughly reconstruct the molecular evolution of the plasmid trio. The revelation that pBT9727 was the first to diverge from the common stem, leaving pXO2 and pAW63 to branch off from an intermediate form some time later, carries several important implications for the ecology of the B. cereus s.l. family. At a very basic level, it highlights the mixed lineage of these plasmids, as attested by their distinct genetic properties (conjugation versus virulence) contrasting with the nearly perfect conservation on all three of the minireplicon of pXO2 [47]; plasmids which were isolated from strains that are treated quite differently, namely as a biopesticide versus a dangerous pathogen. This is particularly relevant in the light of recent incidents linking $B$. cereus sensu stricto strains to cases of anthrax-like pathologies $[21,48,49]$, as well as the discovery that the cereulide genetic determinants of emetic $B$. cereus are located on a plasmid $[7,50]$. Most significantly, it makes a strong case for the pXO2 capsule genes region to be officially designated a pathogenicity island, a hypothesis further validated by the structural features typical of mature PAIs that were identified in this study. The recognition of $\mathrm{pXO} 2$ as a PAI-equipped virulence plasmid would also be consistent with the observation that most of the major known pathogens possess such PAIs, many of these carried by virulence plasmids, and it would put pXO2 on par with pXO1, which is known to carry its own anthrax toxin-bearing PAI. In addition, it should be noted that the configuration of IS231related IRs observed on pXO2 (Fig. 2), which is quite likely due to the insertion of the IS231L element into the PAI after its acquisition by pXO2, entails that a region representing almost the entire PAI, containing all the capsule genes and their associated regulatory elements, can technically be considered an IS231-derived Mobile Insertion Cassette (MIC). As such, this cassette could undergo a transposition event provided a functional IS231 transposase is supplied in trans. Incidentally, this opportunity for virulence genes to be directly mobilized by a mobile genetic element from within a larger PAI is paralleled in pXO1 by the presence in its PAI of a Class II transposon, TnXO1, which carries the anthrax germination operon gerX as its passenger genes [51].

\section{Methods}

\section{Bacterial isolates and PCR amplification}

B. thuringiensis strain HD73 containing pAW63 was grown in liquid $\mathrm{LB}$ medium at $30^{\circ} \mathrm{C} .1 \mathrm{ml}$ cultures grown overnight were centrifuged into a pellet, washed twice in $\mathrm{ddH}_{2} \mathrm{O}$ and resuspended in $250 \mu \mathrm{ldd} \mathrm{H}_{2} 0$. Freshly prepared aliquots of $5 \mu \mathrm{l}$ of resuspended cell solution were used as template in each subsequent $50 \mu \mathrm{l}$ PCR reaction. PCR amplification was performed using 'Hi-Fi polymerase mix' from Fermentas according to the manufacturer's specifications. For target fragments of over $3 \mathrm{~kb}$ it was necessary to adjust the $\mathrm{MgCl}_{2}$ concentration of the reaction mix as well as adding dimethylsulfoxide (DMSO) to optimize yield and specificity. Further details can be obtained upon request. Cloning procedures made use of One Shot ${ }^{\circledast}$ TOP10 Electrocomp ${ }^{\mathrm{TM}}$ E. coli from Invitrogen, and transformation was performed according to the manufacturer's specifications.

\section{Sequencing strategy}

The sequencing strategy took advantage of the previously observed similarity between pAW63 and the virulence plasmid pXO2 from $B$. anthracis $[18,20]$. Further investigation (C. Kuske, pers. comm.) yielded thirty short sequences (400 bp long on average) corresponding to regions of pAW63 which had been shown to hybridize to pXO2. This data was used to construct a backbone sequence on the basis of which primer pairs could be designed to amplify the intervening regions. The resulting amplicons were purified on gel using Qiagen QiaQuick Gel Purification Kit according to the manufacturer's specifications. Amplicons smaller than $5 \mathrm{~kb}$ were directly sequenced from the purified PCR sample, those between 5 and $10 \mathrm{~kb}$ were cloned into sequencing vectors, and those larger than $10 \mathrm{~kb}$ were each subcloned into separate libraries. All cloning procedures were performed using the Topo XL PCR cloning kit of Invitrogen according to the manufacturer's specifications. Amplicons were individu- 
ally sequenced at the Flanders Interuniversity Institute for Biotechnology (VIB) Genetic Service Facility by double strand primer walking following standard procedures with a final accuracy of $99.98 \%$ per amplicon. The primary assembly of individual amplicon sequences was performed using the Seqman software package. The overall assembly quality was improved by sequencing regions of minimum $500 \mathrm{bp}$ in length overlapping the extremities of adjoining amplicons using the same protocol as described above.

\section{Sequence analysis and annotation}

The full assembly of the amplicons, overlapping fragments and the previously published pAW63 replicon was done manually using the Accelrys DS Gene sequence editor. The coordinate start of the sequence was assigned with respect to that of $\mathrm{pXO} 2$ in order to facilitate future comparative analyses between the two plasmids, for which the $B$. anthracis 'Ames Ancestor' strain sequence of pXO2 was used [GenBank:NC_007323]. Potential coding regions were predicted with the prokaryotic gene finder EasyGene [52] using a hidden Markov model (HMM) pretrained on the $B$. anthracis genome. Sequence similarity searches, alignments and further annotation were performed using the BioPerl open software package with standard default BLAST X and ClustalW parameters (details available on request). The BLAST score ratio analysis (BSRA) was performed as described by Rasko et al. [53]. Protein analyses were done using Accelrys DS Gene. Proteome phylogeny analyses were performed using the Tree Building Method (Neighbor Joining, uncorrected) in Accelrys DS Gene. All figures included in this work were generated using the BioPython, GenomeDiagram and ReportLab open software packages. The complete sequence of pAW63 has been deposited in the GenBank database under the accession number DQ025752 [GenBank: DQ025752].

\section{Authors' contributions}

All authors contributed substantially to the study, and all have read and approved the final manuscript.

\section{Acknowledgements}

We are grateful to Lasse Smidt for his many contributions to this project, and to Daniel De Palmenaer for a fruitful collaboration on the analysis of the IS23 I L elements. We would like to thank Dr. Cheryl Kuske for sharing primer sequences and preliminary pAW63 sequence data prior to publication. We also acknowledge the contribution of the VIB Genetic Service Facility http://www.vibgeneticservicefacility.be/ for the sequencing of the plasmid amplicons. This work was supported by the FRIA (Fonds pour la Formation à la Recherche dans I'Industrie et dans l'Agriculture) (grant to G. Van der Auwera), the Carlsberg Foundation (grant to L. Andrup), the National Fund for Scientific Research, and the Université catholique de Louvain.

\section{References}

I. Helgason E, økstad OA, Caugant DA, Johansen HA, Fouet A, Mock $M$, Hegna I, Kolstø $A B$ : Bacillus anthracis, Bacillus cereus, and Bacillus thuringiensis--one species on the basis of genetic evidence. Appl Environ Microbiol 2000, 66(6):2627-2630.

2. Schoeni JL, Wong AC: Bacillus cereus food poisoning and its toxins. J Food Prot 2005, 68(3):636-648.

3. David DB, Kirkby GR, Noble BA: Bacillus cereus endophthalmitis. $\mathrm{Br} J$ Ophthalmol 1994, 78(7):577-580.

4. Mock M, Fouet A: Anthrax. Annu Rev Microbiol 200I, 55:647-67I.

5. Gill SS, Cowles EA, Pietrantonio PV: The mode of action of Bacillus thuringiensis endotoxins. Annu Rev Entomol 1992, 37:6 I 5-636.

6. Fouet $A$, Mock M: Differential influence of the two Bacillus anthracis plasmids on regulation of virulence gene expression. Infect Immun 1996, 64( I 2):4928-4932.

7. Hoton FM, Andrup L, Swiecicka I, Mahillon J: The cereulide genetic determinants of emetic Bacillus cereus are plasmid-borne. Microbiology in press.

8. Christie PJ: Type IV secretion: the Agrobacterium VirB/D4 and related conjugation systems. Biochim Biophys Acta 2004, I 694(1-3):219-234.

9. Berg T, Firth N, Apisiridej S, Hettiaratchi A, Leelaporn A, Skurray RA: Complete nucleotide sequence of pSK4I: evolution of staphylococcal conjugative multiresistance plasmids. J Bacteriol 1998, 180 ( I 7):4350-4359.

10. Morton TM, Eaton DM, Johnston JL, Archer GL: DNA sequence and units of transcription of the conjugative transfer gene complex (trs) of Staphylococcus aureus plasmid pGOI. J Bacteriol I993, I 75( I 4):4436-4447.

II. Schwarz FV, Perreten V, Teuber M: Sequence of the 50-kb conjugative multiresistance plasmid pRE25 from Enterococcus faecalis RE25. Plasmid 200।, 46(3): I70-187.

12. Dougherty BA, Hill C, Weidman JF, Richardson DR, Venter JC, Ross RP: Sequence and analysis of the $60 \mathrm{~kb}$ conjugative, bacteriocin-producing plasmid pMRCOI from Lactococcus lactis DPC3 I 47. Mol Microbiol 1998, 29(4): 1029-1038.

13. Thompson JK, Collins MA: Completed sequence of plasmid pIP50I and origin of spontaneous deletion derivatives. Plasmid 2003, 50(I):28-35.

14. Grohmann E, Muth G, Espinosa M: Conjugative plasmid transfer in gram-positive bacteria. Microbiol Mol Biol Rev 2003, 67(2):277-30I, table of contents.

15. Wilcks A, Jayaswal N, Lereclus D, Andrup L: Characterization of plasmid pAW63, a second self-transmissible plasmid in Bacillus thuringiensis subsp. kurstaki HD73. Microbiology 1998, 144 ( Pt 5): I 263-I270.

16. Okinaka R, Cloud K, Hampton O, Hoffmaster A, Hill K, Keim P, Koehler T, Lamke G, Kumano S, Manter D, Martinez Y, Ricke D, Svensson R, Jackson P: Sequence, assembly and analysis of pXO I and pX02. J Appl Microbiol 1999, 87(2):261-262.

17. Hernandez E, Ramisse F, Ducoureau JP, Cruel T, Cavallo JD: Bacillus thuringiensis subsp. konkukian (serotype $\mathrm{H} 34$ ) superinfection: case report and experimental evidence of pathogenicity in immunosuppressed mice. J Clin Microbiol 1998, 36(7):2 I 38-2 I 39.

18. Wilcks A, Smidt L, økstad OA, Kolstø AB, Mahillon J, Andrup L: Replication mechanism and sequence analysis of the replicon of pAW63, a conjugative plasmid from Bacillus thuringiensis. J Bacteriol 1999, I 8 I (1 0):3193-3200.

19. Riley M: Systems for categorizing functions of gene products. Curr Opin Struct Biol 1998, 8(3):388-392.

20. Pannucci J, Okinaka RT, Williams E, Sabin R, Ticknor LO, Kuske CR: DNA sequence conservation between the Bacillus anthracis pXO2 plasmid and genomic sequence from closely related bacteria. BMC Genomics 2002, 3(I):34.

21. Rasko DA, Altherr MR, Han CS, Ravel J: Genomics of the Bacillus cereus group of organisms. FEMS Microbiol Rev 2005, 29(2):303-329.

22. Francia MV, Fujimoto S, Tille P, Weaver KE, Clewell DB: Replication of Enterococcus faecalis pheromone-responding plasmid pADI: location of the minimal replicon and oriV site and RepA involvement in initiation of replication. J Bacteriol 2004 , I 86( I 5):5003-50|6.

23. Hedberg PJ, Leonard BA, Ruhfel RE, Dunny GM: Identification and characterization of the genes of Enterococcus faecalis plasmid pCF I 0 involved in replication and in negative control of pheromone-inducible conjugation. Plasmid 1996, 35(I):46-57. 
24. Koetje EJ, Hajdo-Milasinovic A, Kiewiet R, Bron S, Tjalsma H: A plasmid-borne Rap-Phr system of Bacillus subtilis can mediate cell-density controlled production of extracellular proteases. Microbiology 2003, I49(Pt I): 19-28.

25. Koraimann G: Bacterial Conjugation: cell-to-cell contact dependent horizontal gene spread. In Microbial Evolution: Gene establishment, survival and exchange Edited by: Miller RV, Day MJ. Washington, D.C. , ASM Press; 2004:III-I24.

26. Yeo HJ, Waksman G: Unveiling molecular scaffolds of the type IV secretion system. J Bacteriol 2004, 186(7):1919-1926.

27. Llosa M, Gomis-Ruth FX, Coll M, de la Cruz Fd F: Bacterial conjugation: a two-step mechanism for DNA transport. Mo Microbiol 2002, 45(I): I-8.

28. Savvides SN, Yeo HJ, Beck MR, Blaesing F, Lurz R, Lanka E, Buhrdorf R, Fischer W, Haas R, Waksman G: VirB I I ATPases are dynamic hexameric assemblies: new insights into bacterial type IV secretion. Embo J 2003, 22(9): 1969-1980.

29. Mills DA, Choi CK, Dunny GM, McKay LL: Characterization of the conjugation system associated with the Lactococcus lactis ssp. lactis plasmid pRSOI. Dev Biol Stand 1995, 85:543-548.

30. Clewell DB, Jaworski DD, Flannagan SE, Zitzow LA, Su YA: The conjugative transposon Tn916 of Enterococcus faecalis: structural analysis and some key factors involved in movement. Dev Biol Stand 1995, 85: I I-I7.

31. Kreft B, Marre R, Schramm U, Wirth R: Aggregation substance of Enterococcus faecalis mediates adhesion to cultured renal tubular cells. Infect Immun 1992, 60(I):25-30.

32. Hill CW, Sandt CH, Vlazny DA: Rhs elements of Escherichia coli: a family of genetic composites each encoding a large mosaic protein. Mol Microbiol 1994, I 2(6):865-87I.

33. Emond E, Dion E, Walker SA, Vedamuthu ER, Kondo JK, Moineau S: AbiQ, an abortive infection mechanism from Lactococcus lactis. Appl Environ Microbiol 1998, 64( I 2):4748-4756.

34. Belhocine K, Plante I, Cousineau B: Conjugation mediates transfer of the LI.LtrB group II intron between different bacterial species. Mol Microbiol 2004, 5 I (5): I 1459- I 469.

35. Hacker J, Kaper JB: Pathogenicity islands and the evolution of microbes. Annu Rev Microbiol 2000, 54:64I-679.

36. Koehler TM: Bacillus anthracis genetics and virulence gene regulation. Curr Top Microbiol Immunol 2002, 27 I: I43-164.

37. De Palmenaer D, Vermeiren C, Mahillon J: IS23I-MIC23I elements from Bacillus cereus sensu lato are modular. Mol Microbiol 2004, 53(2):457-467.

38. Mahillon J, Rezsohazy R, Hallet B, Delcour J: IS23 I and other Bacillus thuringiensis transposable elements: a review. Genetica 1994, 93(I-3): 13-26.

39. Arthur M, Molinas C, Depardieu F, Courvalin P: Characterization of $\operatorname{Tn}$ I 546, a Tn3-related transposon conferring glycopeptide resistance by synthesis of depsipeptide peptidoglycan precursors in Enterococcus faecium BM4|47. J Bacteriol 1993, I75(I): I 17-127.

40. Kurenbach B, Bohn C, Prabhu J, Abudukerim M, Szewzyk U, Grohmann E: Intergeneric transfer of the Enterococcus faecalis plasmid pIP50I to Escherichia coli and Streptomyces lividans and sequence analysis of its tra region. Plasmid 2003, 50(I):86-93.

4I. Lambowitz AM, Zimmerly S: Mobile group II introns. Annu Rev Genet 2004, 38: I-35.

42. Belhocine K, Yam KK, Cousineau B: Conjugative transfer of the Lactococcus lactis chromosomal sex factor promotes dissemination of the LI.LtrB group II intron. J Bacteriol 2005, 187(3):930-939.

43. Dai L, Zimmerly S: ORF-less and reverse-transcriptase-encoding group II introns in archaebacteria, with a pattern of homing into related group II intron ORFs. Rna 2003, 9(I): I4- I9.

44. Toor N, Hausner G, Zimmerly S: Coevolution of group II intron RNA structures with their intron-encoded reverse transcriptases. Rna 200I, 7(8): || 42-|||52.

45. Chen $Y$, Braathen $P$, Leonard C, Mahillon J: MIC23I, a naturally occurring mobile insertion cassette from Bacillus cereus. Mol Microbiol 1999, 32(3):657-668.

46. Reddy A, Battisti L, Thorne CB: Identification of self-transmissible plasmids in four Bacillus thuringiensis subspecies. J Bacteriol 1987, I69(I I):5263-5270.

47. Tinsley E, Naqvi A, Bourgogne A, Koehler TM, Khan SA: Isolation of a minireplicon of the virulence plasmid pXO2 of Bacillus anthracis and characterization of the plasmid-encoded RepS replication protein. J Bacteriol 2004, I86(9):27/7-2723.

48. Rasko DA, Ravel J, økstad OA, Helgason E, Cer RZ, jiang L, Shores KA, Fouts DE, Tourasse NJ, Angiuoli SV, Kolonay J, Nelson WC, Kolstø $A B$, Fraser CM, Read TD: The genome sequence of Bacillus cereus ATCC 10987 reveals metabolic adaptations and a large plasmid related to Bacillus anthracis pXOI. Nucleic Acids Res 2004, 32(3):977-988.

49. Hoffmaster AR, Ravel J, Rasko DA, Chapman GD, Chute MD Marston CK, De BK, Sacchi CT, Fitzgerald C, Mayer LW, Maiden MC, Priest FG, Barker M, Jiang L, Cer RZ, Rilstone J, Peterson SN, Weyant RS, Galloway DR, Read TD, Popovic T, Fraser CM: Identification of anthrax toxin genes in a Bacillus cereus associated with an illness resembling inhalation anthrax. Proc Natl Acad Sci U S A 2004, $101(22): 8449-8454$

50. Ehling-Schulz M, Vukov N, Schulz A, Shaheen R, Andersson M, Martlbauer E, Scherer S: Identification and partial characterization of the nonribosomal peptide synthetase gene responsible for cereulide production in emetic Bacillus cereus. Appl Environ Microbiol 2005, 7I(I): I05-II3.

5I. Van der Auwera G, Mahillon J: TnXOI, a germination-associated class II transposon from Bacillus anthracis. Plasmid 2005, 53(3):25I-257.

52. Larsen TS, Krogh A: EasyGene--a prokaryotic gene finder that ranks ORFs by statistical significance. BMC Bioinformatics 2003 , 4(I):2I.

53. Rasko DA, Myers GS, Ravel J: Visualization of comparative genomic analyses by BLAST score ratio. BMC Bioinformatics 2005, 6(I):2.
Publish with Biomed Central and every scientist can read your work free of charge

"BioMed Central will be the most significant development for disseminating the results of biomedical research in our lifetime. "

Sir Paul Nurse, Cancer Research UK

Your research papers will be:

- available free of charge to the entire biomedical community

- peer reviewed and published immediately upon acceptance

- cited in PubMed and archived on PubMed Central

- yours - you keep the copyright
BiolMedcentral 